\title{
Levetiracetam versus Carbamazepine in Patients with Late Poststroke Seizures: A Multicenter Prospective Randomized Open-Label Study (EpIC Project)
}

\author{
D. Consolia $\quad$ D. Bosco ${ }^{b} \quad$ P. Postorino ${ }^{a} \quad$ F. Galati $^{a} \quad$ M. Plastino ${ }^{b} \quad$ G.F. Perticonic \\ G.A. Ottonello ${ }^{\text {e }}$ B. Passarella ${ }^{f}$ S. Riccig G. Neri $^{d} \quad$ D. Toni ${ }^{\text {h }}$ \\ on behalf of EPIC Study \\ ${ }^{a}$ Operative Unit of Neurology, Jazzolino Hospital, Vibo Valentia, ${ }^{b}$ Department of Neurology, S. Giovanni di Dio \\ Hospital, Crotone, 'Operative Unit of Neurophysiopathology, Monteluce Hospital and d Operative Unit of Neurology, \\ Città di Castello Hospital, Perugia, e Operative Unit of Neurophysiopathology, S. Martino Hospital, Genoa,

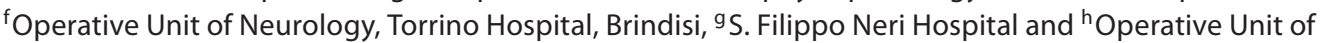 \\ Neurovascular Treatment, Department of Neurology and Psychiatry, La Sapienza University, Rome, Italy
}

\section{Key Words}

Levetiracetam • Carbamazepine • Poststroke seizures • Epilepsy

\begin{abstract}
Background: Strokes are the leading cause of epileptic seizures in adults and account for $50 \%$ of seizures in those over the age of 65 years. The use of antiepileptic drugs to prevent recurrent poststroke seizures is recommended. Methods: One hundred and twenty-eight patients with poststroke seizures were randomly allocated to treatment with either levetiracetam (LEV) or sustained-release carbamazepine (CBZ) in a multicenter randomized open-label study. After a titration study phase ( 2 weeks), the optimal individual dose of trial medication was determined and treatment was continued for another 52 weeks. The primary endpoint was defined as the proportion of seizure-free patients; the secondary endpoints were: evaluation of time recurrence to the first seizure, EEG tracings, cognitive functions and side effects. $R \boldsymbol{e}$ -
\end{abstract}

sults: Of 128 patients, 22 discontinued the trial prematurely; thus a total of 106 patients ( 52 treated with LEV and 54 treated with CBZ) were included in the analysis. The results of the study were as follows: no significant difference in number of seizure-free patients between LEV and CBZ ( $p=0.08)$; time to the first recurrence tended to be longer among patients on LEV; there was no correlation between the therapeutic effect and the EEG findings in either treatment group; LEV caused significantly fewer $(p=0.02)$ side effects than $C B Z$; attention deficit, frontal executive functions and functional scales (Activities of Daily Living and Instrumental Activities of Daily Living indices) were significantly worse in the CBZ group. Conclusions: This trial suggests that LEV may be a valid alternative to $C B Z$ in poststroke seizures, particularly in terms of efficacy and safety. In addition, our results show that LEV has significant advantages over CBZ on cognitive functions. This trial also indicates that LEV in monotherapy is a safe and effective therapeutic option in elderly patients who have suffered epileptic seizures following a stroke.

Copyright @ 2012 S. Karger AG, Basel

\section{KARGER}

Fax +4161306 1234

E-Mail karger@karger.ch

www.karger.com
(C) 2012 S. Karger AG, Basel

$1015-9770 / 12 / 0344-0282 \$ 38.00 / 0$

Accessible online at:

www.karger.com/ced
Domenico Consoli

Operative Unit of Neurology, Jazzolino Hospital

Via P. Fleming

IT-89900 Vibo Valentia (Italy)

E-Mail neurologiavv@live.it 


\section{Introduction}

Stroke is a frequent cause of epilepsy in adults [1]. The frequency of poststroke seizures varies from $2.3 \%$ [2] to $43 \%$ [3]. Epileptic seizures are defined as early epileptic seizures when occurring within 14 days after stroke or late epileptic seizures when occurring more than 2 weeks after stroke. The risk of experiencing late epileptic seizures is $3-5 \%$ in the first year after stroke and $1-2 \%$ thereafter $[4,5]$. Several studies report that the recurrence of seizures is more common among patients with late epileptic seizures than among those with early epileptic seizures $[6,7]$. The risk of epilepsy in some patients with a single seizure associated with stroke is high enough to justify the initiation of anticonvulsant therapy before the second crisis [8]. The occurrence of late seizures is more common in patients who have already experienced early seizures (the risk is about 30\%) [9]. Moreover, development of poststroke epilepsy (that is, recurrent seizures) is more common among patients who have experienced late seizures, with a risk of about $50 \%$ [10]. Possible risk factors for poststroke seizures include: lower-age stroke subtype (especially subarachnoid hemorrhage), lesion localization, stroke severity, a history of diabetes mellitus and the occurrence of poststroke bacterial infections $[5,11]$. Therefore, antiepileptic drugs (AEDs) are prescribed to most patients with late poststroke seizures $[12,13]$.

Levetiracetam (LEV), an (S)- $\alpha$-ethyl-2-oxo-pyrroidine acetamide analog of piracetam, has been approved as adjunctive treatment for partial-onset epileptic seizures in adults [14]. LEV is entirely eliminated through renal excretion, and the potential for drug interactions is absent or negligible [15]. Its pharmacokinetic profile includes minimal protein binding and a lack of hepatic metabolism [13]. The tolerability profile with respect to effects on memory and cognitive function is good as well [16].

This multicenter open-label randomized study was designed (EpIc Project) to evaluate the proportion of seizure-free patients among patients with late poststroke seizures, treated either with LEV or sustained-release carbamazepine (CBZ). Secondary outcome measures were: (1) to compare treatment retention treatment from the first intake in the two treatment groups (i.e. the rate of premature discontinuation for any reason), (2) to evaluate the differences in cognitive functions and quality of life in the two groups at the end of treatment, (3) to assess changes in the electroencephalogram (EEG) at the end of the treatment period versus baseline and (4) to evaluate treatment tolerability at the end of treatment.

\section{Materials and Methods}

\section{Study Design}

We used the criteria of the Commission on Classification and Terminology of the International League against Epilepsy to differentiate between simple partial, complex partial, and secondarily generalized seizures. Patients with late poststroke seizures were randomized to either $\mathrm{CBZ}$ or LEV in a 1:1 ratio and entered the open-label treatment phase. Randomization numbers were sequentially assigned across centers, and a computer-generated randomization scheme was used to provide balanced blocks of patients for each treatment group within each center.

The treatment phase was divided into periods, flexible titration ( 2 weeks) and maintenance (3-54 weeks). Clinical, electroencephalographic and neuropsychological examinations were performed at the baseline visit $\left(\mathrm{V}_{0}\right)$, after the titration phase $\left(\mathrm{V}_{2}\right)$ and at the end of the study $\left(\mathrm{V}_{3}\right.$; week 54$)$. Seizure frequency was assessed by 'seizure diaries' filled in by patients and/or family members.

LEV Treatment. In the first and second week, LEV was given at a dose of $250 \mathrm{mg}$ twice daily (500 mg/day). After the third week, it was given at a dose of $500 \mathrm{mg}$ twice daily (1,000 mg/day). This daily dose range and the twice daily schedule were to be continued during the subsequent 52-week maintenance period. After 54 weeks, LEV might be discontinued at the discretion of the investigator, with the same mode of initial titration. For patients who experienced other seizures, the dosage of LEV was increased gradually to a maximum of $3,000 \mathrm{mg} /$ day. The investigator was free to decrease the dose if the patient had side effects. Patients exhibiting seizures at a daily LEV dose of 3,000 mg were considered nonresponders and were switched to another AED. In this case, the patient was excluded from the study. No concomitant AEDs were allowed.

CBZ Treatment. In the first week, CBZ was given at a dose of $100 \mathrm{mg} /$ day for 1-3 days; the dosage was subsequently increased to $200 \mathrm{mg} /$ day (100 mg twice daily). In the second and third week, the dosage was gradually increased to $300 \mathrm{mg}$ twice daily $(600 \mathrm{mg} /$ day). This daily dose and the twice daily schedule were to be continued during the subsequent 52 -week maintenance period. After 54 weeks, CBZ might be discontinued at the discretion of the investigator, with the same mode of initial titration. For patients who experienced other seizures, the dosage of CBZ was increased gradually to a maximum of $1,600 \mathrm{mg} /$ day. The investigator was free to decrease the dose if the patient had side effects. Patients exhibiting seizures at a daily CBZ dose of $1,600 \mathrm{mg}$ were considered nonresponders and were switched to another AED. No concomitant AEDs were allowed.

Written informed consent was obtained from all patients. The design and conduct of this trial were approved by ethics committees. One hundred and twenty-eight patients aged $\geq 18$ years with poststroke initially late epileptic seizures, seen in the Cerebrovascular Unit between September 2008 and March 2009 were prospectively studied. Because of the small number of recruited patients, the random procedure was extended until January 2011 in the Vibo Valentia and Crotone Neurology Centers. We included patients with seizures occurring from 2 weeks to 3 years after their stroke. The type of stroke was divided into hemorrhagic or ischemic, and the etiologic subtypes of ischemic stroke were classified according to the Trial of ORG 10172 in Acute Stroke Treatment (TOAST) criteria [17]. Patients who had seizures only in spe- 
cific circumstances, such as electrolyte imbalance and other metabolic conditions, and those diagnosed with epilepsy before the stroke were not included in this study. Other exclusion criteria were: pregnancy, history of status epilepticus, neoplastic disease, severe stroke (Rankin scale $>3$ ), Mini Mental Scale Examination (MMSE) $<24$, known allergy or contraindications to the use of LEV and/or CBZ, life expectancy $<1$ year, the onset of the first seizure could not be determined or occurred more than 2 weeks after the visit, myoclonic seizures, dysphagia, poor compliance, brain injury, impairment of consciousness. No previous AED treatments were allowed except for emergency treatments of seizures during a maximum period of 4 weeks prior to trial entry, nor were drugs allowed during the 30 days prior to randomization that could interfere with the study drugs.

In the two groups we evaluated: the frequency of seizures during the treatment period, the retention of treatment from the first intake, the differences in cognitive functions and quality of life at the end of treatment, the changes in the EEG at the end of the treatment period versus baseline and the tolerability at the end of treatment. Assessments were made by an observer blinded to the treatment arm to which patients were assigned.

\section{Cognitive Measures}

An extensive neuropsychological testing battery assessing mainly memory and executive functions was administered to all subjects. The neurologists who administered the tests were completely unaware of the treatment carried out. The neuropsychological testing battery included: the MMSE to evaluate global cognitive functioning [18]; Logical Memory from the Wechsler Memory Scale-Revised [19]. Visual Memory was assessed with the Benton visual memory test [20], the Digital Span Test, which explores attention and some executive functions [21], the Stroop Test to investigate the inhibition process [22]; Raven's Coloured Progressive Matrices Test for nonverbal reasoning [23] and the Corsi span and supraspan learning test [24]. In addition, the scores for physical activities of daily living were estimated using the Activities of Daily Living (ADL) index and the InstrumentalADL (IADL) [25]; depression was assessed with the Geriatric Depression Scale [26].

\section{EEG Assessment}

EEG examinations were performed at the beginning of the trial $\left(\mathrm{V}_{0}\right)$ and at the end of each maintenance period $\left(\mathrm{V}_{2}\right.$ and $\left.\mathrm{V}_{3}\right)$. EEG assessment included the following patterns: (1) normal EEG; (2) focal slowing; (3) diffuse slowing; (4) sharp waves; (5) spikes;

(6) focal seizure patterns and (7) diffuse seizure patterns.

EEG assessment was carried out centrally and the examiner was unaware of the treatment allocation.

\section{Statistical Analysis}

Both median and mean values were used for estimation of the location parameters. Standard deviation was used as an index of dispersion. Efficacy analyses were performed on an intentionto-treat basis, including all patients who received at least one dose of study drug. Categorical variables were compared between groups using the $\chi^{2}$ test. Differences between CBZ and LEV on the primary study endpoint were expressed by the odds ratio as an estimate of the relative risk. Relative risk is presented with $95 \%$ confidence intervals. The t test for independent samples was used to compare continuous variables according to treatment. The time of the first recurrence of a seizure after baseline was called an 'event' and assessed with the Kaplan-Meier method; the time of the seizure was calculated as the difference in weeks between the date of the visit in which the crisis was established and the date of the baseline visit $\left(\mathrm{V}_{0}\right)$. Seizure-free patients were defined as 'censored' at the last observation time (study end or last date available). The difference between treatments was assessed with the log-rank test. The primary efficacy variable was the proportion of seizure-free patients who had had at least one seizure assessment during the maintenance period. The original sample size (630 patients) was calculated to detect a difference in seizure recurrence from 30 to $20 \%$ with $\alpha=0.05$ and $\beta=0.2$. The sample size was chosen to detect a significant difference at the 5\% level (two-sided) with a power of $69 \%$. Assuming seizure freedom rates of 30 and $20 \%$ for LEV and CBZ, respectively, 106 patients in the maintenance period would be needed for the primary analysis. All comparisons were performed using the SAS 9.2 statistical package. Differences or changes were considered to be statistically significant if $p$ values were $\leq 5 \%$.

\section{Results}

Randomization included enrollment of 630 patients but was stopped prematurely due to financial reasons. Between September 2008 and March 2009, a total of 128 patients with poststroke seizures were randomized: 62 to LEV and 66 to CBZ. Of 128 patients, 22 discontinued the trial prematurely (10 allocated to LEV and 12 to CBZ): 8 due to poor compliance ( 4 allocated LEV and 4 to CBZ) and 7 due to severe adverse events (SAEs) (3 allocated to LEV and 4 to CBZ), and 7 due to unknown causes ( 3 allocated to LEV and 4 to CBZ). Thus a total of 106 patients (52 treated with LEV and 54 treated with CBZ) were included in the analysis (fig. 1).

Table 1 summarizes the demographic characteristics of the patient population. There were no significant differences between treatment groups with respect to age and sex. Patients had partial seizures with or without secondary generalization, without differences between the two treatment groups. Twenty-seven patients displayed tonic-clonic seizures with partial onset. Concomitant diseases were present in $66(72 \%)$ patients, $30(28 \%)$ allocated to the LEV group and 36 (34\%) to the CBZ group. Twenty-eight patients (18 in the LEV group and 10 in the CBZ group) had past and 66 had current pathologies (25 in the LEV group and 41 in the CBZ group). Among the past pathologies, stroke or the consequences of stroke prevailed (9 in the LEV group and 3 in the CBZ group). During the 1-year follow-up, another 13 patients (10\%), 7 in the LEV group and 6 in the CBZ group, reported disease recurrence (5 with transient ischemic attacks and 8 
Fig. 1. Discontinuation/completion sum-

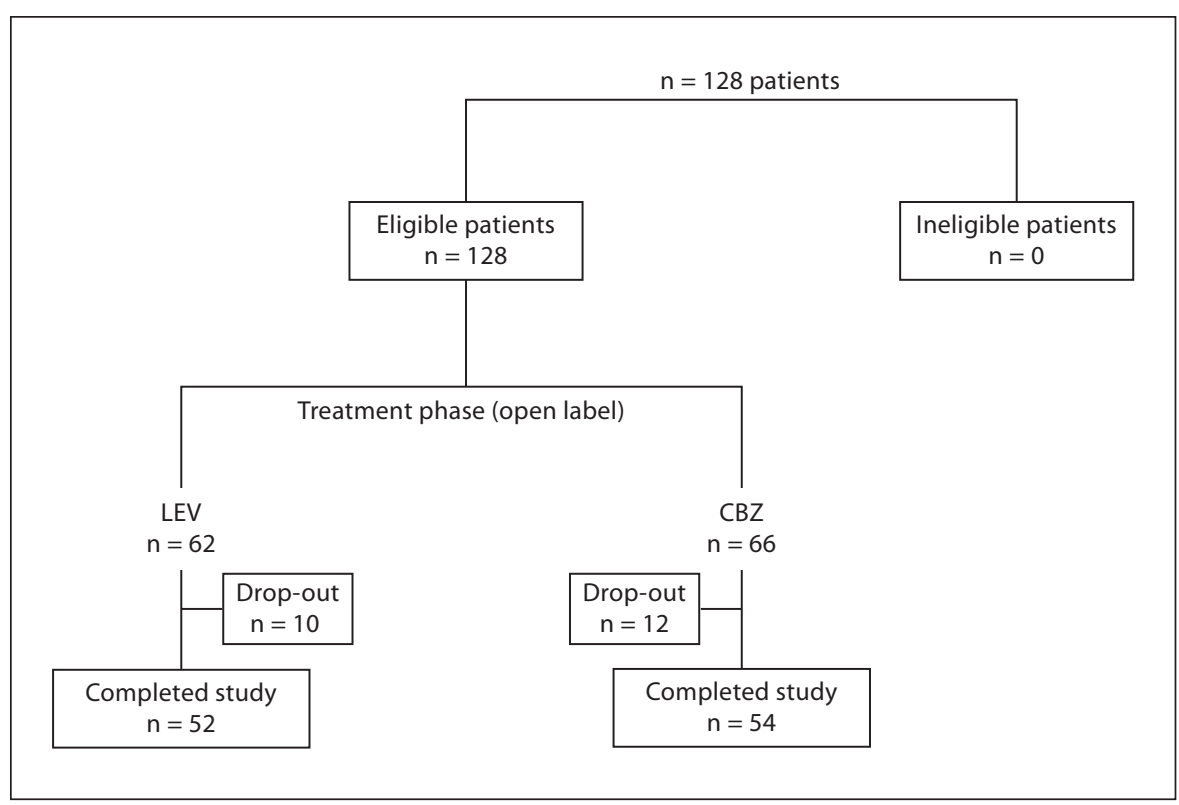

with a second stroke). Nevertheless, all patients completed the study; among the current pathologies, hypertension prevailed (11 in the LEV group and 13 in the CBZ group), followed by diabetes (5 in the LEV group and 3 in the CBZ group). Type of stroke and pathogenic subtypes of ischemic stroke were equally represented in both groups.

At the baseline visit before randomization, 84 (79\%) patients, of whom $42(80 \%)$ patients in the LEV group and 42 (87\%) in the CBZ group, had experienced 1-3 seizures, for a total of 90 seizures (46 in the LEV group and 44 in the CBZ group). After initiation of the treatment, 49 (94\%) patients taking LEV and 46 (85\%) taking CBZ were seizure free during the maintenance period (table 2). Recurrence of seizures was reported in 3 patients of the LEV group ( 1 seizure in 1 patient, 3 seizures in 1 patient and 11 seizures in the 1 patient) and 8 patients of the CBZ group ( 1 seizure in 4 patients, 3 seizures in 2 patients and 5 seizures in 1 patient).

The primary efficacy variable (seizure free) analyzed by the log-rank test was favorable for LEV though not reaching statistical significance $(\mathrm{p}=0.08)$. The KaplanMeier survival curves of time to recurrence after the first seizure during the maintenance period in both treatment groups are shown in figure 2. The LEV/CBZ seizure freedom odds ratio calculated by relative risk indicates that LEV-treated patients had a 2.36 times $(95 \%$ confidence interval 0.39-14.15) lower risk to experience a recurrent seizure than patients treated with CBZ.
Table 1. Clinical and demographic baseline data of all randomized patients

\begin{tabular}{|c|c|c|c|}
\hline & $\begin{array}{l}\text { LEV } \\
(\mathrm{n}=52)\end{array}$ & $\begin{array}{l}\text { CBZ } \\
(\mathrm{n}=54)\end{array}$ & $\mathrm{p}$ \\
\hline Mean age $\pm S D$, years & $74.1 \pm 11.3$ & $69.7 \pm 13.2$ & 0.21 \\
\hline Sex, female/male & $23 / 29$ & $25 / 29$ & 0.09 \\
\hline $\mathrm{PS}, \mathrm{n}$ & $35(67 \%)$ & $39(72 \%)$ & 0.32 \\
\hline GTCS, n & $17(33 \%)$ & $15(28 \%)$ & 0.21 \\
\hline \multicolumn{4}{|l|}{ Type of stroke, $n$} \\
\hline Ischemic & $38(73 \%)$ & $41(76 \%)$ & 0.47 \\
\hline Hemorrhagic & $14(27 \%)$ & $13(24 \%)$ & 0.92 \\
\hline \multicolumn{4}{|l|}{ Etiology of ischemic stroke, $\mathrm{n}$} \\
\hline Atherothrombotic & $29(76 \%)$ & $30(75 \%)$ & 0.12 \\
\hline Cardioembolic & $6(15.7 \%)$ & $7(17 \%)$ & 0.93 \\
\hline Other & $3(7.8 \%)$ & $3(7.5 \%)$ & 0.23 \\
\hline \multicolumn{4}{|l|}{ Concomitant diseases, $\mathrm{n}$} \\
\hline Total pathologies & 43 & 51 & 0.54 \\
\hline Past & 18 & 10 & 0.62 \\
\hline Current & 25 & 41 & 0.06 \\
\hline \multicolumn{4}{|l|}{ Past pathologies, $\mathrm{n}$} \\
\hline Stroke or outcomes of stroke & 9 & 3 & 0.05 \\
\hline Hypertension & 11 & 13 & 0.39 \\
\hline Diabetes mellitus & 5 & 3 & 0.34 \\
\hline
\end{tabular}

PS = Partial seizures with or without secondarily generalized seizures; GTCS = generalized tonic-clonic seizures without partial onset. 
Fig. 2. Kaplan-Meier curves estimate of the percentage of seizure-free patients receiving sustained-release CBZ or LEV. Time was calculated as the difference in weeks between the visit at which the crisis was diagnosed and the baseline visit $\left(\mathrm{V}_{0}\right)$. Seizure-free patients were defined as 'censored' at the last observation time.

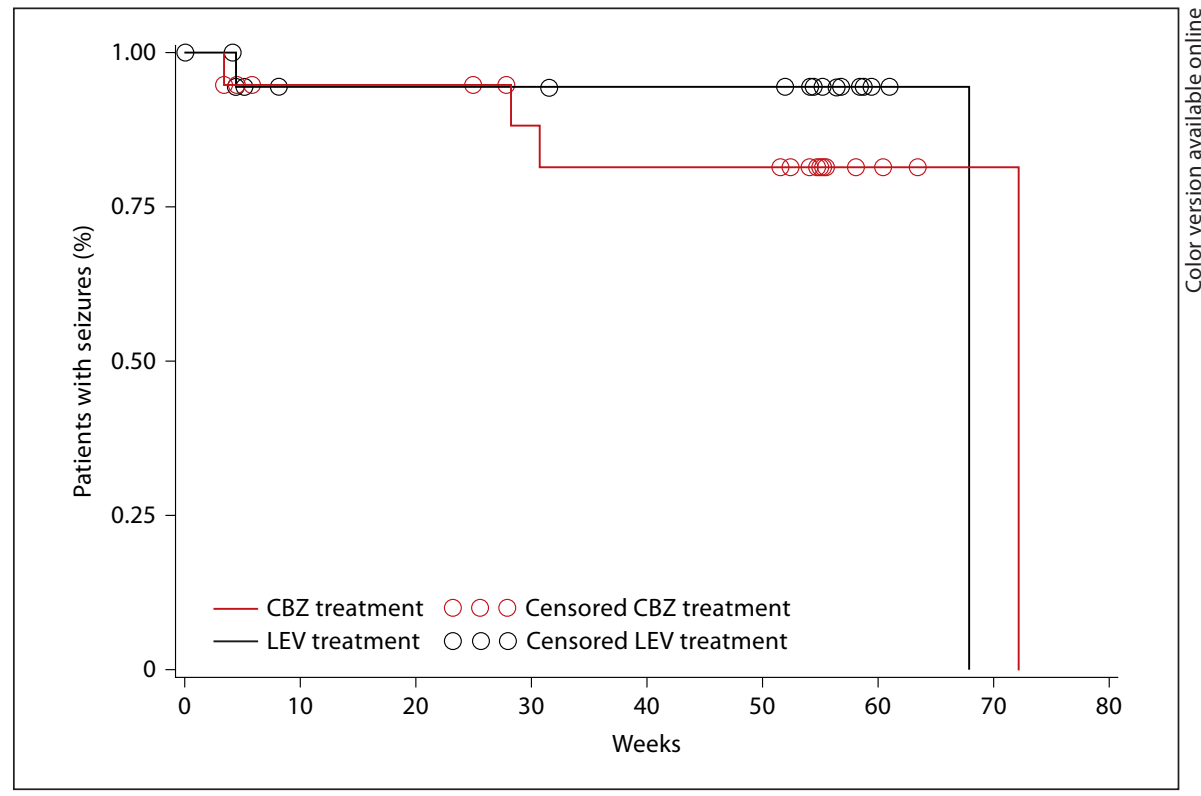

Table 2. Number and percentage of seizure-free patients and abnormal EEG at $\mathrm{V}_{0}$ and $\mathrm{V}_{3}$

\begin{tabular}{|c|c|c|c|}
\hline Variable & $\operatorname{LEV}(\mathrm{n}=52)$ & $\mathrm{CBZ}(\mathrm{n}=54)$ & $\mathrm{p}$ \\
\hline \multicolumn{4}{|l|}{ Seizure-free, $n$} \\
\hline Baseline $\left(\mathrm{V}_{0}\right)$ & $10 / 52(19 \%)$ & $12 / 54(22 \%)$ & 0.2 \\
\hline Maintenance period $\left(\mathrm{V}_{3}\right)$ & $49 / 52(94 \%)$ & $46 / 54(85 \%)$ & 0.08 \\
\hline \multicolumn{4}{|l|}{ EEG abnormalities, $n$} \\
\hline \multicolumn{4}{|l|}{ Total abnormalities } \\
\hline Baseline $\left(\mathrm{V}_{0}\right)$ & $47 / 52(90 \%)$ & $47 / 53(88)^{\mathrm{a}}$ & 0.3 \\
\hline End of the study $\left(\mathrm{V}_{3}\right)$ & $45 / 50(90 \%)^{b}$ & $45 / 50(90 \%)^{\mathrm{c}}$ & 0.36 \\
\hline \multicolumn{4}{|l|}{ Focal slowing } \\
\hline Baseline $\left(\mathrm{V}_{0}\right)$ & $28 / 52(54 \%)$ & $28 / 53(53 \%)^{\mathrm{a}}$ & 0.13 \\
\hline End of the study $\left(\mathrm{V}_{3}\right)$ & $26 / 50(52 \%)^{b}$ & $26 / 52(50 \%)^{c}$ & 0.21 \\
\hline \multicolumn{4}{|l|}{ Sharp waves } \\
\hline Baseline $\left(\mathrm{V}_{0}\right)$ & $13 / 52(25 \%)$ & $14 / 53(26 \%)$ & 0.2 \\
\hline End of the study $\left(\mathrm{V}_{3}\right)$ & $11 / 50(22 \%)$ & $12 / 50(24 \%)$ & 0.16 \\
\hline \multicolumn{4}{|l|}{ Spikes } \\
\hline Baseline $\left(\mathrm{V}_{0}\right)$ & $6 / 52(11 \%)$ & $3 / 53(5.6 \%)$ & 0.06 \\
\hline End of the study $\left(\mathrm{V}_{3}\right)$ & $6 / 50(12 \%)^{b}$ & $3 / 50(6 \%)$ & 0.05 \\
\hline $\begin{array}{l}\text { a The EEG was not p } \\
\mathrm{b} \text { The EEG was not p } \\
{ }^{c} \text { The EEG was not p }\end{array}$ & med in $1 p$ & nt. & \\
\hline
\end{tabular}

The EEG data are shown in table 2. At baseline, focal epileptiform abnormalities were recorded in 47 (90\%) LEV- and in 47 (88\%) CBZ-treated patients. Of the 47 LEV-treated patients, 28 had 'focal slowing', 13 had 'sharp
Table 3. Number of patients with AEs who received either LEV or CBZ

\begin{tabular}{llll}
\hline Variable & LEV $(\mathrm{n}=52)$ & CBZ $(\mathrm{n}=54)$ & $\mathrm{p}$ \\
\hline Patients with AEs & $17 / 52$ & $21 / 54$ & 0.02 \\
Number of AEs & 27 & 34 & 0.02 \\
\hline AEs & & & \\
$\quad$ Syncope & 1 & 0 & \\
Allergy & 5 & 16 & \\
Visual disturbance & 0 & 1 & \\
Ataxia & 1 & 2 & \\
Drowsiness & 6 & 5 & \\
Abdominal pain & 3 & 0 & \\
Diarrhea & 0 & 2 & \\
Leukopenia & 0 & 1 & \\
Increased liver parameters & 0 & 1 & \\
Fatigue & 7 & 1 & \\
Vertigo & 2 & 0 & \\
$\quad$ Headache & 2 & 1 & \\
\hline
\end{tabular}

waves' and 6 had 'spikes'; in the CBZ group, 30 patients had 'focal slowing', 14 had 'sharp waves' and 3 had 'spikes'. Four patients with abnormal EEGs (sharp waves) at baseline had normal EEGs at the end of treatment (2 patients in the LEV group and 2 patients in the CBZ group). Drug dose reduction was reported in 4 cases in the LEV group and in 2 patients in the CBZ group. In the remaining patients, the EEG pattern was unmodified versus baseline. 
Table 4. Neuropsychological findings with daily activities at baseline $\left(\mathrm{V}_{0}\right)$ and end $\left(\mathrm{V}_{3}\right)$ of the study in the two groups

\begin{tabular}{|c|c|c|c|c|c|c|}
\hline Test & \multicolumn{3}{|l|}{$\mathrm{V}_{0}$} & \multicolumn{3}{|l|}{$\mathrm{V}_{3}$} \\
\hline \multicolumn{7}{|l|}{ Attention } \\
\hline Digit span: forward & $3.2 \pm 1.4$ & $3.4 \pm 1.8$ & 0.12 & $3.4 \pm 1.3$ & $4.1 \pm 1.5$ & 0.03 \\
\hline Digit span: backward & $1.8 \pm 0.9$ & $2 \pm 0.7$ & 0.13 & $1.8 \pm 0.9$ & $2.3 \pm 1.1$ & 0.03 \\
\hline Stroop: colour reading & $48.6 \pm 24$ & $45.4 \pm 26$ & 0.05 & $40.3 \pm 24.6$ & $38.9 \pm 23$ & 0.02 \\
\hline Verbal semantic & $14 \pm 8.1$ & $14.8 \pm 10$ & 0.21 & $15.6 \pm 9.1$ & $15.2 \pm 9.8$ & 0.13 \\
\hline Verbal fluency & $4 \pm 1.2$ & $3.8 \pm 1.1$ & 0.22 & $4.2 \pm 1.3$ & $3.9 \pm 1.2$ & 0.24 \\
\hline Wechsler memory scale & $8.5 \pm 4.2$ & $8.3 \pm 5.1$ & 0.12 & $5 \pm 2.4$ & $4.8 \pm 2.1$ & 0.14 \\
\hline Raven's matrices & $25.5 \pm 9.9$ & $25.3 \pm 6.9$ & 0.14 & $26.5 \pm 6.4$ & $26 \pm 5.8$ & 0.11 \\
\hline Corsi span and supraspan & $5.6 \pm 0.9$ & $5.8 \pm 0.7$ & 0.13 & $4.4 \pm 1.2$ & $4.8 \pm 1.2$ & 0.12 \\
\hline IADL & $13.2 \pm 1.6$ & $14 \pm 3.1$ & 0.08 & $15.2 \pm 2.1$ & $16.5 \pm 4.6$ & 0.05 \\
\hline
\end{tabular}

Values are expressed as mean $\pm \mathrm{SD}$ unless otherwise indicated.

Side effects were recorded at every visit and classified by the investigator as mild, moderate or severe. Any side effect classified as severe led to immediate discontinuation of the treatment. Moderate side effects led to reduction of the dose while side effects classified as mild were only recorded. Table 3 reports SAEs and adverse events (AEs) in the two groups. Of all randomized patients, 7 discontinued the trial prematurely because of SAEs: 3 in the LEV group and 4 in the CBZ group).

Of the 3 SAEs in the LEV group, 2 (continuous episodes of severe drowsiness) were certainly correlated to the treatment and 1 was a syncopal episode, which required hospitalization. SAEs leading to drug withdrawal in the CBZ group were: allergic reactions (2 patients), visual loss (1 patient) and drowsiness (1 patient). For the primary tolerability analysis, the long-rank test on time to premature discontinuation due to AEs showed no differences between the treatment groups $(p=0.3)$. Of the 106 patients (52 treated with LEV and 54 treated with CBZ) who completed the study, 14 patients in the LEV group had at least $1 \mathrm{AE}$, for a total of $24 \mathrm{AEs}$, while 17 patients in the CBZ group presented at least $1 \mathrm{AE}$, for a total of 31 AEs $(\mathrm{p}=0.02)$.

Neuropsychological findings are summarized in table 4. Attention deficit on digit span at the end of followup was greater in the CBZ group ( $\mathrm{p}=0.03)$. In addition, frontal executive functions, as indicated by the word reading of the Stroop test, were significantly worse in the CBZ group than in the LEV group $(p=0.02)$. MMSE, Wechsler Memory Scale-Revised, Verbal Semantic, Verbal Fluency, Raven's Coloured Progressive Matrices, Corsi test and the Geriatric Depression Scale did not differ significantly between the two groups. On the functional scales of ADL and IADL, impairment of the activities of daily living was greater in the CBZ than in the LEV treatment $(\mathrm{p}=0.05)$.

\section{Discussion}

This small trial suggests that LEV may be better tolerated than CBZ and have similar efficacy in patients with poststroke partial seizures or generalized tonic-clonic seizures. European guidelines recommend the use of AEDs to prevent recurrent poststroke seizures, but prophylactic administration to patients who have not sustained a seizure is not recommended $[27,28]$. Three randomized controlled trials compared a number of different AEDs in poststroke seizures. One study was performed in patients $>60$ years of age with various diagnoses including stroke [29]; another study was performed in children and adolescents with diagnoses including stroke [30] and the last study was performed in stroke patients only [31]. The findings from these studies suggest that la- 
motrigine treatment for poststroke seizures is as effective as CBZ and relatively better tolerated [31]. Alvarez-Sabin et al. [32] also studied the tolerability and efficacy of gapapentin in patients with late-onset poststroke seizures. Among the 71 patients evaluated, seizures recurred in $18 \%$; side effects were recorded in $38 \%$, and required discontinuation of the drug in only 2 cases. The authors suggested that gabepentin monotherapy is useful and safe for late poststroke seizures In some countries, such as the UK, sodium valproate remains a very popular AED for the treatment of poststroke seizures [33] although there is no evidence supporting this practice [29]. The efficacy and tolerability of LEV in patients aged $\geq 60$ with poststroke seizures have been recently investigated by Gulnihal et al. [34], who reported that $82.4 \%$ of patients were seizure free and $20.6 \%$ had side effects.

To our knowledge, this is the first investigation that evaluated the efficacy and tolerability of LEV versus sustained-release CBZ in patients with late poststroke seizures (EpIc Project). In our study, the seizure-free ratio between the two treatment groups tended to favor LEV, but the differences did not reach statistical significance ( $p=0.08)$. Nevertheless, the Kaplan-Meier survival curves of the time to recurrence following the first seizure indicate that LEV-treated patients had a 2.36 times lower risk of experiencing seizure recurrences than patients treated with CBZ. Besides, LEV was better tolerated, as indicated by the overall lower incidence of side effects as compared to sustained-release CBZ. These side effects were mainly mild and did not require suspension of treatment. Of the 3 SAEs leading to study discontinuation, only 2 were definitely related to the treatment. Another relevant result of this trial was the effect of AEDs on cognitive performance. New AEDs might have less influence on cognitive functions, but this feature has not been systematically studied. AEDs have both negative and positive effects on cognition and behavior [35]. To our knowledge, only one study evaluated the cognitive outcome in patients treated with LEV or CBZ monotherapy as primary treatment or as replacement of previous therapies. Helmstaedter and Witt [36] suggested a mild but definitely higher cognitive outcome with LEV than with CBZ treatment. Our data confirm the superiority of LEV compared with CBZ in many cognitive domains. This study has some limitations: it is primarily an open-label study; several factors (i.e. extent and/or location of the poststroke lesion) that may contribute to common poststroke cognitive outcome measures were not assessed, and this may affect the final evaluation. Another limitation is the small sample size because the power of the study is equal to $69 \%$ for a significant difference at the $5 \%$ level. Initially, the power was calculated on a sample of 128 patients, but as we had no information about the efficacy and tolerability in 22 patients who discontinued the study prematurely, we had to reassess the power of the study on 106 patients.

In conclusion, the results of this trial indicate that LEV and CBZ were equally efficacious in adults with poststroke partial and generalized tonic-clonic seizures, and suggest that LEV may have advantages in terms of tolerability and effects on cognitive functions. Further studies on larger samples of patients are required to confirm the efficacy and/or tolerability of LEV in the treatment of poststroke seizures.

\section{Disclosure Statement}

The authors have no conflict of interest to disclose. None of the authors have received financial support or funding for the research covered in this article.

\section{References}

$\checkmark 1$ Beghi E, D’Alessandro R, Beretta S, Consoli D, Crespi V, Delaj L, Gandolfo C, Greco G, La Neve A, Manfredi M, Mattana F, Musolino R, Provinciali L, Santangelo M, Specchio LM, Zaccara G; Epistroke Group: Incidence and predictors of acute symptomatic seizures after stroke. Neurology 2011;77:1776-1778.

-2 Mohr JP, Caplan LR, Melski JW, Goldstein RJ, Duncan GM, Kistler JP, Pessin MS, Bleich HL: The Harvard Cooperative stroke Registry: a prospective registry. Neurology 1978 ; 28:754-762.
3 Meyer JS, Charney JZ, Rivera VM, Mathew NT: Cerebral embolization prospective clinical analysis of 42 cases. Stroke 1971;2:541-554.

-4 So EL, Annegers JF, Hauser WA, O’Brien PC, Whisnant JP: Population-based study of seizure disorders after cerebral infarction. Neurology 1996;46:350-355.

-5 Burn J, Dennis M, Bamford J, Sandercock P, Wade D, Warlow C: Epileptic seizures after a first-ever stroke: the Oxfordshire Community Stroke Project. Br Med J 1997;315:15821587.
6 Shinton RA, Gill JS, Melnick SC, Gupta AK, Beevers DG: The frequency, characteristics and prognosis of epileptic seizures at late onset of stroke. J Neurol Neurosurg Psychiatry 1988;51:272-276.

7 Lesser RP, Luders H, Dinner DS, Morris HH: Epileptic seizures due to thrombotic and embolic cerebrovascular disease in older patients. Epilepsia 1985;26:622-630.

$\checkmark 8$ Labovitz DL, Hauser WA: Preventing strokerelated seizures. When should anticonvulsant be started? Neurology 2003:60:365-366. 
$>9$ Kilpatrick CJ, Davis SM, Tress BM, Rossiter SC, Hopper JL, Vandendriesen ML: Epileptic seizures in acute stroke. Arch Neurol 1990; 47:157-160.

10 Krakow K, Sitzer M, Rosenow F, Steinmetz, Foerch C; for the Arbeitsgruppe Schlaganfall Hessen: Predictors of acute poststroke seizure. Cerebrovasc Dis 2010;30:584-589.

11 Olsen TS: Post-stroke epilepsy. Curr Atheroscler Rep 2001;3:340-344.

$>12$ Alvarez-Sabin J, Montaner J, Padro L, Molina CA, Rovira R, Codina A, Quintana M: Gabapentin in late-onset poststroke seizures. Neurology 2002;59:1991-1993.

- 13 Kutlu G, Gomceli YB, Unal Y, Inan LE: Leviracetam monotherapy for late poststroke seizures in the elderly. Epilepsy Behav 2008;13: 542-544.

14 Shorvon SD, Lowenthal A, Janz D, Bielen E, Loiseau P: Multicenter double-blind, randomized, placebo-controlled trial of leviracetam as add-on therapy in patients with refractory seizures. Epilepsia 2000;41:11791186.

15 Perruca E: Clinical pharmacokinetics of new generation antiepileptic drugs at the extremes of age. Clin Pharmacokinet 2006;45: 351-363.

-16 French J: A systemic review of the safety profiles of levetiracetam: a new antiepileptic drug. Epilepsy Res 2001;47:77-90.

$\checkmark 17$ Goldstein LB, Jones MR, Matchar DB, Edwards LJ, Hoff J, Chilukuri V, Armstrong SB, Homer RD: Improving the reliability of stroke subgroup classification using the trial of ORG 10172 in acute stroke treatment (TOAST) criteria. Stroke 2001;32:1091-1098.

18 Folstein MF, Folstein SE, McHugh PR: Minimental state. A practical method for grading the cognitive state of patients for the clinical. J Psychiatr Res 1975;12:189-198.

19 Weschsler DA: Manual for the Wechsler Adult Intelligence Scale-revised. New York, Psychological Corporation, 1981.
20 Campo P, Morales M: Reliability and norma tive data for the Bentos Visual Form Discrimination Test. Clin Neuropsychol 2003; 17:220-225

21 Wechsler D: WAIS-III Administration and Scoring Manual, San Antonio, Harcourt Brace. 1997.

22 Stroop JR: Studies of interference in serial verbal reactions. J Exp Psychol 1935; 18:643652.

23 Raven JC: Coloured Progressive Matrices Sets A, AB, B. London, Lewis, 1962.

24 Capitani E, Leiacona M: Composite neuropsychological batteries and demographic correction: standardization based on equivalent score, with a review of published data. The Italian Group for the neuropsychological Study of Ageing. J Clin Exp Neuropsychol 1997; 19:795-809.

25 Lincoln NB, Edmans JA: A revalidation of the Rivermead ADL scale for elderly patients with stroke. Age Ageing 1990;19:9-24.

26 Shiekl JL, Yesavage JA: Geriatric Depression Scale (GDS): Recent evidence and development of a shorter version. Clin Gerontol 1986;5:165-173.

27 EUSI Writing Committee, Olsen TS, Langhorne P, Diener HC, Hennerici M, Ferro J, Sivenius J, Wahlgren NG, Bath P: European Stroke Initiative executive Committee and the EUSI Writing Committee. European Stroke Initiative Recommendations for Stroke Managment - update 2003. Cerebrovasc Dis 2003;16:311-337.

28 The European Stroke Initiative Writing Committee and the Writing Committee for the EUSI Executive Committee. European Stroke Initiative Recommendations for the Management of Intracranial Haemorrhage. I. Spontaneous intracerebral haemorrhage. Cerebrovasc Dis 2006;22:294-316.

29 Rowan AJ, Ramsay RE, Collins JF, Pryor F, Boardman KD, Uthman BM, Spitz M, Frederick T, Towne A, Carter GS, Marks W, Felicetta J, Tomyanovich ML, VA Cooperative Study 428 Group: New onset geriatric epilepsy: a randomized study of gabapentin, lamotrigine and carbamazepine. Neurology 2005;64:1868-1873.
30 Marson AG, Al-Kharusi AM, Alwaidh M, Appleton R, Baker GA, Chadwick DW, Cramp C, Cockerell OC, Cooper PN, Doughty J, Eaton B, Gamble C, Goulding PJ, Howell SJ, Hughes A, Jackson M, Jacoby A, Kellett M, Lawson GR, Leach JP, Nicolaides P, Roberts R, Shackley P, Shen J, Smith DF, Smith PE, Smith CT, Vanoli A, Williamson PR; SANAD study group: The SANAD study of effectiveness of carbamazepine, gabapentin, lamotrigine, oxocarbamazepine, or topiramate for treatment of partial epilepsy: an unblinded randomized controlled trial. Lancet 2007;369:1000-1015.

31 Gilad R, Sadeh M, Rapoport A, Dabby R, Boaz M, lampl Y: Monotherapy of lamotrigine versus carbamazepine in patients with poststroke seizure. Clin Neuropharmacol 2007;30:189-195.

32 Alvarez-Sabin J, Montaner J, Padro I, et al: Gabapentin in late onset poststroke seizures. Neurology 2002;59:1991-1993.

33 Stephen LJ: Drug treatment of epilepsy in elderly people: focus on valproic acid. Drugs Aging 2003;20:141-152.

34 Gulnihal K, Yasemin BG, Yasemin U, Levent EI. Levipiracetam monotherapy for late poststroke seizures in the elderly. Epilepsy Behav 2008;13:542-544.

35 Meador KJ: Cognitive effects of epilepsy and of antiepileptic medications; in Wyllie E (ed): The Treatment of Epilepsy: Principles and Practices. Phhiladelphia, Lippincott Williams \& Wilkins, 2005, pp 1185-1195.

36 Helmstaedter C, Witt JA: Cognitive outcome of antiepileptic treatment with levipiracetam versus carbamazepine monotherapy: a non-interventional surveillance trial. Epilepsy Behav 2010;18:74-80. 